\title{
A 2-year observational study of patients with relapsing-remitting multiple sclerosis converting to glatiramer acetate from other disease-modifying therapies: the COPTIMIZE trial
}

\author{
Tjalf Ziemssen • Ovidiu A. Bajenaru • Adriana Carrá • Nina de Klippel · João C. de Sá • Astrid Edland • \\ Jette L. Frederiksen - Olivier Heinzlef - Klimentini E. Karageorgiou • Rafael H. Lander Delgado • \\ Anne-Marie Landtblom • Miguel A. Macías Islas • Niall Tubridy • Yossi Gilgun-Sherki
}

Received: 17 January 2014/Revised: 14 July 2014/ Accepted: 15 July 2014/Published online: 14 August 2014

(C) The Author(s) 2014. This article is published with open access at Springerlink.com

\begin{abstract}
Studies suggest that patients with relapsingremitting multiple sclerosis (RRMS) who do not benefit from other disease-modifying treatments (DMTs) may benefit from converting to glatiramer acetate (GA). COPTIMIZE was a 24-month observational study designed to assess the disease course of patients converting to GA $20 \mathrm{mg}$ daily from another DMT. Eligible patients had converted to GA and had received prior DMT for 3-6 months, depending on the reasons for conversion. Patients were assessed at baseline and at $6,12,18$, and 24 months. In total, 672 patients from 148 centers worldwide were included in the analysis. Change of therapy to
\end{abstract}

R. H. Lander Delgado: Deceased.

T. Ziemssen ( $\square)$

Neurologische Universitätsklinik, Klinikum Carl Gustav Carus, Fetscherstraße 74, 01307 Dresden, Germany

e-mail: Tjalf.Ziemssen@uniklinikum-dresden.de

O. A. Bajenaru

Carol Davila University of Medicine and Pharmacy, Bucharest,

Romania

A. Carrá

Hospital Britanico de Buenos Aires, Buenos Aires, Argentina

N. de Klippel

Virga Jessaziekenhuis, Hasselt, Belgium

J. C. de Sá

Hospital de Santa Mari, Hasselt, Belgium

A. Edland

Central Hospital of Buskerud, Drammen, Norway

J. L. Frederiksen

Glostrup Hospital, University of Copenhagen, Glostrup,

Denmark
GA was prompted primarily by lack of efficacy (53.6\%) or intolerable adverse events (AEs; $44.8 \%$ ). Over a 24-month period, $72.7 \%$ of patients were relapse free. Mean annual relapse rate decreased from 0.86 [95\% confidence interval (CI) $0.81-0.91]$ before the change to $0.32(95 \% \mathrm{CI}$ $0.26-0.40 ; p<0.0001)$ at last observation, while the progression of disability was halted, as the Kurtzke Expanded Disability Status Scale (EDSS) scores remained stable. Patients improved significantly $(p<0.05)$ on measures of fatigue, quality of life, depression, and cognition; mobility scores remained stable. The results indicate that changing RRMS patients to GA is associated with positive treatment outcomes.

O. Heinzlef

Tenon Hospital, Paris, France

K. E. Karageorgiou

General Hospital of Athens, Athens, Greece

A.-M. Landtblom

Department of Neurology and Department of Clinical and Experimental Medicine, University of Linköping, Linköping, Sweden

A.-M. Landtblom

Department of Medical Specialists and Department of Medicine and Health Sciences, Linköping University, Motala, Sweden

M. A. Macías Islas

Central University of Guadalajara, Guadalajara, Jalisco, Mexico

N. Tubridy

School of Medicine and Medical Science, Dublin University,

Dublin, Ireland

Y. Gilgun-Sherki

Teva Pharmaceuticals Industries Ltd, Petach Tikva, Israel 
Keywords Disease-modifying therapy $\cdot$ Glatiramer acetate $\cdot$ Multiple sclerosis $\cdot$ RRMS

\section{Introduction}

Multiple sclerosis (MS) is a chronic, progressive, autoimmune diffuse inflammatory disease of the central nervous system [1]. Historically, the disease and the efficacy of MS treatments were measured by the extent to which clinical progression was slowed or halted, using relapse rates or the progression of disability $[2,3]$. However, we now know that other considerations must also be taken into account, including fatigue, quality of life (QoL), etc. [4]. At least $30 \%$ of patients show a suboptimal response to first-line disease-modifying treatments (DMTs) for relapsing-remitting multiple sclerosis (RRMS) during the first year of treatment [5]. There are no acceptable criteria to guide physicians when converting from one first-line DMT to another, and such decisions are generally based on the physician's judgment.

Studies have shown that the three most common reasons why physicians in clinical practice convert an MS patient's medication are lack of efficacy or suboptimal response, [5, 6] intolerable drug-induced adverse events (AEs) [7, 8], and the development of neutralizing antibodies [9-11], which are known to block the biological activity of interferon (IFN) and natalizumab therapy [12]. It has been suggested that clinical observations such as relapse rate and disability or findings of magnetic resonance imaging (MRI) may be used to define criteria for converting from one DMT to another in clinical practice $[12,13]$. One study analyzed whether the first relapse and time from the first to second relapse would be able to predict treatment failure [14]. However, none of these criteria has proved useful in determining whether a patient would benefit from a treatment change.

Converting therapy within the IFN- $\beta$ class may not always benefit the patient [15]. Patients who present with neutralizing antibodies during IFN treatment do not benefit from converting from one IFN to another or from continuous therapy with any subcutaneous IFN- $\beta$ preparation [15]. Conversely, studies have demonstrated that there is a clinical benefit in changing either from one class of first-line DMT to another or to second-line treatments [13, 16-18]. With some DMTs (e.g. natalizumab, which is indicated for patients for whom IFN therapy has not been effective), the use of escalating doses has been proven to improve efficacy compared with converting to another DMT [19]. However, despite its efficacy profile, the safety and tolerability of natalizumab are a concern because of the risk of progressive multifocal leukoencephalopathy (PML) [20].
The copolymer glatiramer acetate (GA; Copaxone) is approved as a 20-mg daily subcutaneous (s.c.) injection for reducing relapse frequency in patients with RRMS [21]. Post-marketing experience with GA includes more than 1.88 million patient-years of exposure and, in some patients, more than 20 consecutive years of treatment [22]. Two prospective open-label studies have shown a beneficial effect of GA for subjects who did not benefit from previous sequential IFN treatment, either because of lack of perceived clinical effects or AEs [13, 17]. The COPTIMIZE trial was designed to provide insight into patients' outcomes and attitudes toward converting to GA when another DMT is ineffective or intolerable. This also allowed investigators to assess the impact of the mild adverse effect profile of GA, which differs in many ways from other DMTs, and the positive impact of GA on QoL parameters [23-25].

\section{Methods}

Study design

COPTIMIZE was a 2-year international, multicenter, prospective, non-interventional, longitudinal, and observational study conducted in 148 study centers across 19 countries. Included were patients who had converted from another DMT to GA $20 \mathrm{mg}$ daily within 3-6 months of screening.

An electronic case report form (eCRF) was completed by attending neurologists (investigators) to assess the disease course and rationale for converting treatment to GA. Data were collected by means of standardized eCRF on a password-protected website, at baseline and then at 6-month intervals for a total of five data collection time points over 24 months. Baseline assessment included patients' demographic characteristics, MS disease history, reasons for changing medication, annualized relapse rate (ARR) in the 2 years before the conversion, expanded disability status scale (EDSS)/mobility score measured within 2 years before the conversion and at recruitment, MRI data, cognitive functions by Paced Auditory Serial Addition Test (PASAT) [26], and impact of fatigue on daily activities by Modified Fatigue Impact Scale (MFIS; the effects of fatigue on physical, cognitive, and psychosocial functioning) [27]. Patients answered 21 questions on fatigue severity, with scores ranging from 'never' (0) to 'highly' (4), which denotes severe fatigue.

Assessments at 6-month intervals included relapses within the previous 6 months and the EDSS/mobility score; the EDSS assessment was performed via the Neurostatus $e$ test [28]. Confirmed progression (i.e. worsening of the EDSS from baseline to final examination) was defined as an increase of one point if the baseline EDSS score was 
between 0 and 5 , and by an increase of 0.5 points if the baseline score was $>5.0$. Changes in function were assessed by the Functional Assessment of Multiple Sclerosis (FAMS) [29]. Scores on the FAMS range between 0.00 and 176.00 points, with an increase in score indicating an increase in functional abilities. Depression was measured by the Center for Epidemiological Studies Depression Scale (CES-D) [30]. CES-D scores ranged from 0 to 60 points, with higher scores indicating more symptoms of depression during the past week.

\section{Patients}

To be included, patients had to have a diagnosis of RRMS, to have converted to GA within 3 months before recruitment, and to have available ARR and EDSS data acquired in the year before inclusion. Patients could have been treated with any DMT for up to 6 months before the treatment conversion, if the change was due to unverified drug inefficacy or AEs.

Patients were classified based on their individual premedication: 'de novo' patients had not received any pharmaceutical MS medication, 'converter' patients had received another kind of DMT before recruitment, and 'post-chemotherapy' patients had received chemotherapeutic medication before recruitment.

\section{Study endpoints}

The primary study endpoint was disease course of subjects converted from one DMT class (IFN) to another (GA) as measured by ARR before and after the conversion, annualized rate of deterioration (ARD: rate of deterioration as measured by mean EDSS), and mobility score in the year before and following the change to GA.

Secondary endpoints included reasons for changing DMT; characteristics of patients failing to benefit from previous DMT; QoL changes measured by FAMS following GA conversion; impact of fatigue on daily activities, measured by the MFIS; change in rates of depression as evaluated by CES-D; and changes in AEs before and after the conversion to GA.

This study was conducted in accordance with the 18th World Medical Assembly (Helsinki) recommendations and amendments, as well as guidelines for Good Epidemiology Practice. Patients' personal data and investigator data included in the sponsor database were treated in compliance with all local applicable laws and regulations.

\section{Statistical analyses}

The intention-to-treat cohort, consisting of all enrolled subjects who took at least one dose of GA, was used for all efficacy and safety assessments. Descriptive procedures were used to represent data. Tests of significance (signed rank test and binomial test) were used to measure changes in efficacy parameters from baseline to final examination. Wilcoxon signal rank was used within groups for EDSS, MFIS, QoL, CES-D, and PASAT (excluding ARR). Kruskal-Wallis was used between groups for EDSS. Poisson regression within and between groups was used for ARR. ARR and ARD before and after the conversion was analyzed using repeated measures analysis of covariance using the maximum likelihood ratio. Log transformation was implemented to the ARR and ARD to establish if there was a significant deviation of ARR and ARD from normality (i.e. if $p<0.001$ on the Shapiro-Wilk test).

\section{Results}

\section{Patient disposition}

A total of 672 patients were enrolled in the study. Data on 555 patients $(82.6 \%)$ were available at 365 days, and data on $423(63.0 \%)$ were available at 730 days. The mean duration of observation was 594.7 days $[ \pm$ standard deviation $(\mathrm{SD})=221.3$ ] in 634 patients who had one or more examinations. Table 1 details patient demographics and disease characteristics.

\section{Baseline demographics and patient classification}

Demographics and disease characteristics are shown in Table 1. Of the 672 patients enrolled, 640 (95.2\%) were classified as 'converter' patients (had received other DMT before enrollment), and the efficacy analysis was restricted to these patients. Nine $(1.3 \%)$ were classified as 'postchemotherapy' patients, and 23 patients $(3.4 \%)$ were missing classification data. In converted patients, a change of therapy to GA was prompted primarily by lack of efficacy $(343 / 640 ; 53.6 \%)$ or intolerable AEs (287/640; $44.8 \%$ ), caused by the corresponding premedication. [Note: The number of patients who changed to GA due to a lack of efficacy (343) and the number that changed due to AEs (287) sums to 630 , not 640 , as there are multiple reasons aside from these two that were cited by patients for changing therapy]. In the majority of converted patients $(553 / 640 ; 86.4 \%)$, only a single DMT agent had been used before the conversion to GA therapy. Eighty patients $(12.5 \%)$ had received two DMT agents, and six patients $(0.9 \%)$ had received three DMT agents before the change to GA. One patient $(0.2 \%)$ was missing information on number of prior DMT treatments received.

Of the patients converted, documentation on type of DMT was available for 617 patients and missing for 23 
Table 1 Baseline demographics and disease characteristics

\begin{tabular}{|c|c|c|}
\hline Characteristics & Patients with data & Overall \\
\hline Female gender, $n(\%)$ & 672 & $476(70.8)$ \\
\hline Mean age, years (SD) & 672 & $39.9(10.2)$ \\
\hline $\begin{array}{l}\text { Mean duration of disease since } \\
\text { onset, mo (SD) }\end{array}$ & 615 & $97.2(78.9)$ \\
\hline $\begin{array}{l}\text { Mean time since MS diagnosis, mo } \\
\text { (SD) }\end{array}$ & 632 & $69.7(61.3)$ \\
\hline $\begin{array}{l}\text { Median ARR measured over the } \\
\text { past } 2 \text { years before GA (SD) }\end{array}$ & 625 & $0.86(0.67)$ \\
\hline $\begin{array}{l}\text { Distribution of patients by ARR } \\
\text { range, } n(\%)\end{array}$ & 660 & \\
\hline$<1$ & & $329(49.9)$ \\
\hline$\geq 1$ and $<3$ & & $318(48.2)$ \\
\hline$\geq 3$ & & $13(2.0)$ \\
\hline Clinical type of MS, $n(\%)$ & 657 & \\
\hline $\begin{array}{l}\text { RRMS with incomplete } \\
\text { remissions }\end{array}$ & & $264(40.2)$ \\
\hline RRMS with complete remission & & $383(58.3)$ \\
\hline Clinically isolated syndrome & & $1(0.2)$ \\
\hline Other & & $9(1.4)$ \\
\hline $\begin{array}{l}\text { Mean EDSS score measured over } \\
\text { the past } 2 \text { years before GA (SD) }\end{array}$ & 878 & $2.8(1.7)$ \\
\hline $\begin{array}{l}\text { Mean EDSS score at time of } \\
\text { conversion (SD) }\end{array}$ & 600 & $3.0(1.9)$ \\
\hline Mobility score, $n(\%)$ & 595 & \\
\hline Asymptomatic & & $111(18.7)$ \\
\hline Able to walk unaided $>500 \mathrm{~m}$ & & $336(56.5)$ \\
\hline $\begin{array}{l}\text { Able to walk unaided } \\
\text { for }<500 \mathrm{~m}\end{array}$ & & $60(10.1)$ \\
\hline Walking with unilateral support & & $51(8.6)$ \\
\hline Walking with bilateral support & & $22(3.7)$ \\
\hline Need of wheelchair outdoors & & $15(2.5)$ \\
\hline MRI data available, $n(\%)$ & 672 & $193(41.0)$ \\
\hline
\end{tabular}

$A R R$ annualized relapse rate, EDSS Expanded Disability Status Scale, $G A$ glatiramer acetate, $M R I$ magnetic resonance imaging, $M S$ multiple sclerosis, $R R M S$ relapsing-remitting multiple sclerosis, $S D$ standard deviation

patients. Most patients converted (589/617) (95.5\%) had received IFN- $\beta$ before converting (Fig. 1).

Table 2 details the baseline disease characteristics of those patients who were converted because of lack of efficacy or because of AEs. The clinical type of disease, disease activity over the past 2 years, and the decision to convert were significantly different between these two groups. A greater proportion of patients who converted because of lack of efficacy presented with RRMS with incomplete remissions, while most who converted because of AEs had RRMS with complete remissions. Exacerbations tended to be rare in both groups. However, exacerbations of disease were more frequent in those who were converted because of lack of efficacy, while stable disease was more prominent in those who were converted because of AEs. While, in most cases, the decision to convert was made solely by the patient's physician, a mutual decision was more common among the patients who converted because of AEs (Table 2). The majority of patients who converted because of AEs discontinued IFN therapy because of flu-like symptoms [180/287 (62.7 \%); Table 3].

Among the nine patients classified as being 'post-chemotherapy', the most common reasons for converting were worsening of EDSS $(n=7)$ and severity of relapses $(n=4)$, followed by high lesion load on MRI $(n=2)$ and a high relapse rate $(n=1)$. Multiple reasons for converting could be recorded for a single patient. All nine patients had undergone escalation therapy, seven had received mitoxantrone, one had received cyclophosphamide, and one cyclophosphamide followed by IFN.

\section{Efficacy of GA}

\section{$A R R$}

Data on ARRs before converting to GA and during the study were available for 625 patients. The majority of these patients $[n=458 / 625(73.3 \%)]$ experienced less than 0.25 relapses/year while receiving GA therapy (Fig. 2). Overall, patients experienced a significant reduction in the mean number of relapses from baseline while on GA therapy from 0.86 to 0.32 (mean change $-0.54 ; p<0.0001$ Chi squared; Fig. 3). Reductions in ARR from baseline were significant regardless of whether patients converted because of lack of efficacy or AEs (mean change -0.66 and -0.36 , respectively; $p<0.0001$ in both groups; Fig. 3). However, the decrease in ARR was significantly greater in patients converting for lack of efficacy versus AEs $(p=0.0021)$.

\section{Confirmed EDSS change}

Data on 399 patients with at least one confirmed EDSS progression after baseline examination were evaluated. The proportion of patients without confirmed progression (343/ 399 patients, $86.0 \%$ ) was significantly higher than with confirmed progression (56/399 patients; $14.0 \% ; p<0.0001$, binominal-test with $H_{0}$ proportion $=50 \%$ ). When analyzed by reason for conversion only, patients who converted because of intolerable AEs had a significant increase in EDSS from baseline $(+0.17 ; p=0.0265$, Fig. $4 \mathrm{a})$ but there was no significant difference between the values in the two groups.

\section{Mobility score}

A total of 542 patients had at least one mobility score after the baseline examination. The majority of patients $(n=348 ; 64.2 \%)$ did not experience any worsening in 
Fig. 1 Type of diseasemodifying therapy used by patients before converting to glatiramer acetate in patients with previous type known $(n=617)$. IFN interferon, i.m intramuscular, i.v. intravenous, s.c subcutaneous

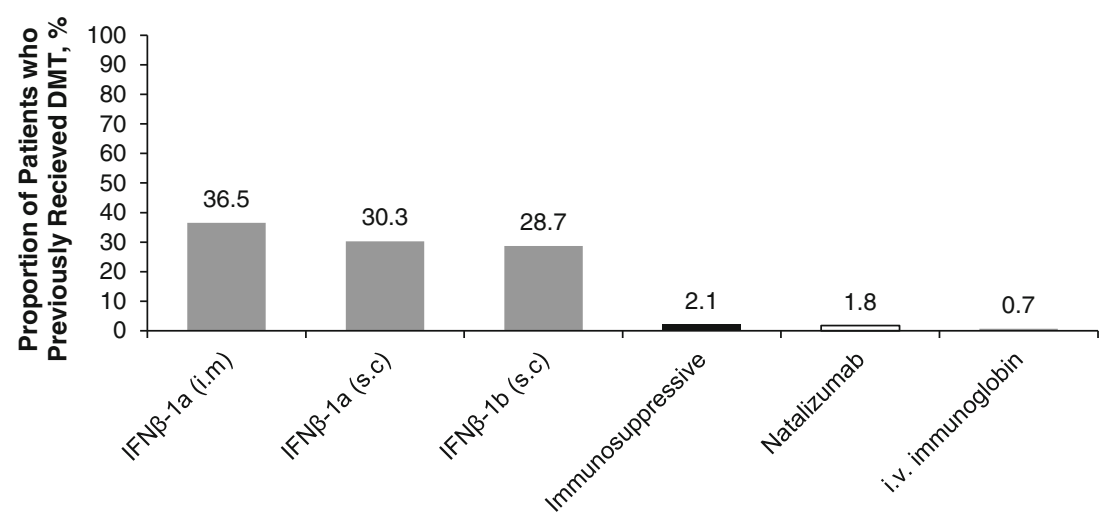

Table 2 Disease characteristics of patients converted to glatiramer acetate because of lack of efficacy or adverse events $(n=630)$

\begin{tabular}{|c|c|c|c|}
\hline Characteristics & $\begin{array}{l}\text { Lack of } \\
\text { efficacy } \\
(n=343)\end{array}$ & $\begin{array}{l}\text { Adverse } \\
\text { events } \\
(n=287)\end{array}$ & $p$ value \\
\hline \multicolumn{3}{|c|}{ Clinical disease type over the past 2 years, $\%$} & $<0.0001$ \\
\hline $\begin{array}{l}\text { RRMS with complete } \\
\text { remissions }\end{array}$ & 30.1 & 50.3 & \\
\hline $\begin{array}{l}\text { RRMS with incomplete } \\
\text { remissions }\end{array}$ & 67.5 & 49.3 & \\
\hline Other & 2.4 & 0.5 & \\
\hline \multicolumn{3}{|c|}{ Activity of disease over the past 2 years, $\%$} & $<0.0001$ \\
\hline Stable MS & 8.9 & 23.7 & \\
\hline $\begin{array}{l}\text { Exacerbations rare }(<1 \\
\text { relapse/year) }\end{array}$ & 35.9 & 47.3 & \\
\hline $\begin{array}{l}\text { Slow progression }(<1 \\
\text { point increase in EDSS in } \\
\text { the last year) }\end{array}$ & 16.1 & 9.4 & \\
\hline $\begin{array}{l}\text { Frequent exacerbations }(\geq 1 \\
\text { relapse/year) }\end{array}$ & 31.5 & 16.3 & \\
\hline $\begin{array}{l}\text { Fast progression }(\geq 1 \text { point } \\
\text { increase in EDSS in the } \\
\text { last year) }\end{array}$ & 3.2 & 1.0 & \\
\hline Could not be classified & 4.4 & 2.5 & \\
\hline \multicolumn{3}{|c|}{ Decision to convert therapy made by, $\%$} & $<0.0001$ \\
\hline Physician & 86.2 & 59.9 & \\
\hline Patient & 2.8 & 7.4 & \\
\hline Both & 10.9 & 32.7 & \\
\hline
\end{tabular}

EDSS Expanded Disability Status Scale, $M S$ multiple sclerosis, RRMS relapsing remitting MS

mobility A total of $103(19.0 \%)$ patients reported better mobility, while $91(16.8 \%)$ reported worse mobility. The difference in the numbers of patients showing improvement or worsening was not significant by binominal test with $H_{0}$ proportion $=50 \%(p=\mathrm{NS})$.

\section{Impact on fatigue}

Data on 287 patients with MFIS scores were available for evaluation. Overall, mean MFIS scores decreased significantly from baseline to final examination, with a difference of -3.59 points $\pm 15.05, p<0.0001$; Table 4 . The reduction in fatigue was greater in patients who converted because of lack of efficacy ( -6.01 points from baseline; $p=0.0006$ ), compared with those who converted because of AEs ( -2.16 points; $p=$ NS; Fig. $4 b)$.

\section{Change in $Q o L$}

A total of 218 patients had available QoL data at baseline and at the final examination.

A significant improvement in QoL score of 5.94 $( \pm 31.57 ; p=0.0227)$ from baseline to final examination was reported (Table 4). QoL improved regardless of the reasons for treatment conversion. Greater improvement was observed in patients who converted because of AEs $(+10.81$ points from baseline; $p=0.0120)$, compared with those who converted because of lack of efficacy $(+6.62$ points; $p=$ NS; Fig. 4c).

\section{Depression}

Data on 299 patients were available for evaluation. There was a significant improvement overall in the depression score following the conversion to GA therapy ($1.50 \pm 10.84$ from baseline; Table 4). Improvement was most commonly observed in patients who were converted because of lack of efficacy ( -4.48 points from baseline; $p<0.0001)$. No improvement was reported in those who converted because of AEs ( +0.58 points; $p=$ NS; Fig. $4 d)$.

\section{Cognition changes}

In the 72 patients for whom cognition (PASAT) data were available, scores improved by a mean of $4.29 \pm 9.28$ $(p<0.0001$; Table 4). Improvement in cognition was observed in patients who converted because of AEs $(+3.26$ points from baseline; $p=0.0088$ ), as well as in those who converted because of lack of efficacy $(+4.33$ points from 
Table 3 Reasons for discontinuing interferon treatment before study entry among patients converted to glatiramer acetate because of intolerable adverse events $(n=287)$

Patients responded with up to three possible reasons

\begin{tabular}{lc}
\hline Reason & $\begin{array}{l}\text { Patients, } \\
n(\%)\end{array}$ \\
\hline $\begin{array}{l}\text { Flu-like } \\
\text { symptoms }\end{array}$ & $180(62.7)$ \\
Subjective & $83(28.9)$ \\
Skin reactions & $51(17.8)$ \\
Blood work & $29(10.1)$ \\
Others & $64(22.3)$ \\
Not specified & $2(0.7)$ \\
\hline
\end{tabular}

baseline; $p=$ NS; Fig. 4e). Both baseline and final scores were notably higher in the group that converted because of AEs (Fig. 4e).

\section{Patient reporting of efficacy}

Among the 660 patients with available data, only 49 patients $(7.4 \% ; p<0.0001)$ reported that GA was less effective than their previous DMT, while significantly more patients [348 $(52.7 \%)]$ reported that GA treatment was more effective than their previous DMT, and 263 patients $(39.9 \%)$ reported no difference.

Safety and tolerability

A total of 196 AEs occurred in 104 patients [15.5\% of all patients $(n=672)]$, with the majority of events deemed probably [104 events in 56 patients $(8.3 \%)$ ] or possibly related to GA therapy [ 45 events in 26 patients $(3.8 \%)$ ]. Most common AEs by preferred term and system organ class are shown in Table 5 in addition to AEs by severity reported. 174 of all 672 patients $(25.9 \%)$ terminated GA treatment during the observation period. Table 6 details the physician- and patient-reported reasons for termination.
Fig. 2 Distribution of annualized relapse rates (ARRs) before and during glatiramer acetate therapy $(n=625)$. Patients with a very high annualized relapse rate terminated glatiramer acetate treatment after a short period of observation because of relapses

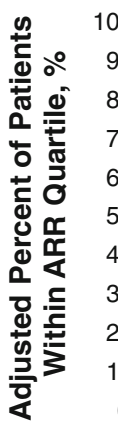

- Pre-conversion Post-conversion

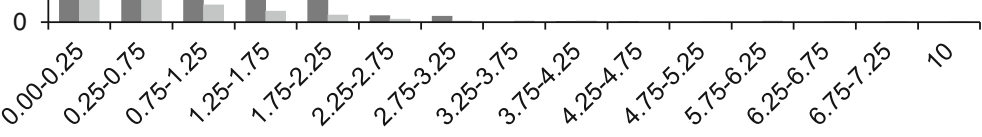

ARR Quartile

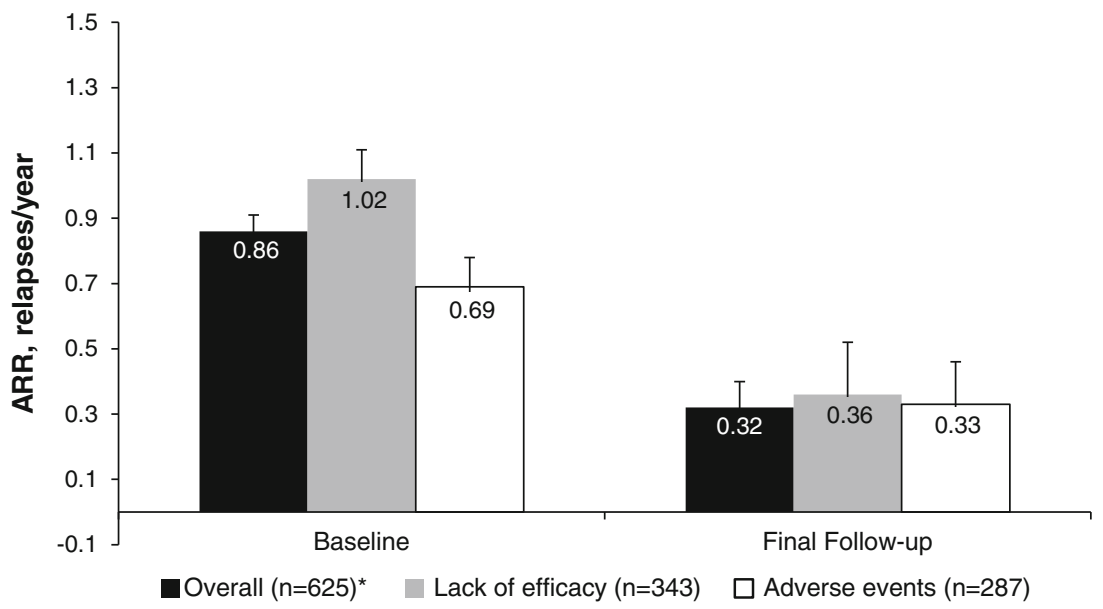

Fig. 3 Change in annualized relapse rate (ARR) in all patients receiving glatiramer acetate $(\mathrm{GA})$ therapy $(n=625)$ and in patients with known reason for the conversion to GA (Asterisk denotes that the overall number of patients with ARR data does not equal the sum of the number of patients who converted to GA due to lack of efficacy and adverse events because of double counting of patients who reported both reasons for converting). All reductions in ARR within groups were statistically significant $(p<0.0001)$ 

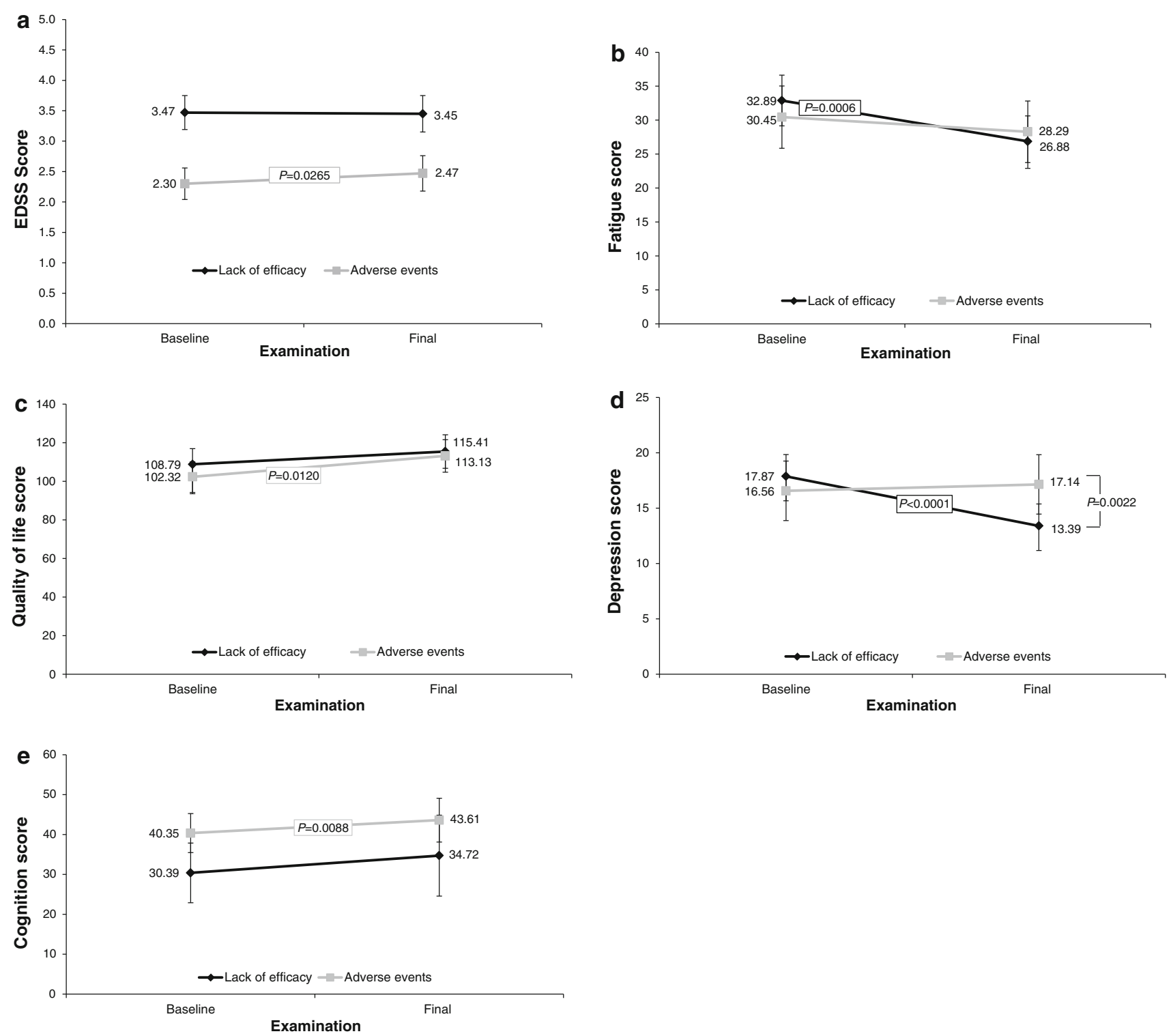

Fig. 4 a Change in Expanded Disability Status Scale (EDSS) score in patients converted to glatiramer acetate, by the reason for the conversion. b Change in fatigue score (Modified Fatigue Impact Scale) in patients converted to glatiramer acetate, by the reason for the conversion. c Change in quality of life score (Functional Assessment of Multiple Sclerosis) in patients converted to glatiramer

\section{Discussion}

It is reported that patients with RRMS frequently convert DMT because their original therapy is not optimally effective or produces intolerable AEs [6, 7, 9, 12, 17-19]; those were the main reasons for converting to GA therapy in this study. Depending on the reasons for converting, lack of efficacy or adverse reactions, patients may have a greater or lesser response to the new agent.

ARR is an important indication of the inflammatory component of MS. In the COPTIMIZE study, ARR

acetate, by the reason for the conversion. d Change in depression score (Center for Epidemiological Studies Depression Scale) in patients converted to glatiramer acetate, by the reason for the conversion. e Change in cognition score (paced auditory serial addition test) in converting patients by the reason for the conversion

was significantly reduced from baseline after converting to GA, both in patients who converted because of lack of efficacy and those who converted because of AEs.

No significant changes in EDSS scores were observed in patients who were converted to GA therapy. However, it is important to note that following the conversion to GA, a greater proportion of patients had no confirmed progression, as measured by the EDSS; only modest changes in EDSS scores from baseline were observed. Subgroup analysis revealed EDSS scores to be higher at both baseline 
Table 4 Change in secondary efficacy endpoints from baseline to final observation of all patients irrespective of previous treatment or reason for conversion

\begin{tabular}{|c|c|c|c|c|}
\hline Scale, mean $(95 \% \mathrm{CI})$ & Patients with data $(n)$ & Baseline & Final & $p$ value \\
\hline Fatigue, MFIS & 287 & $31.94(29.67-34.22)$ & $28.36(26.00-30.72)$ & $<0.0001$ \\
\hline Quality of life, FAMS & 218 & $102.67(97.78-107.57)$ & $108.61(103.43-113.80)$ & 0.0227 \\
\hline Depression, CES-D & 299 & $16.13(14.85-17.40)$ & $14.63(13.38-15.88)$ & 0.0111 \\
\hline Cognition, PASAT & 72 & $37.46(33.93-40.99)$ & $41.75(37.79-45.71)$ & $<0.0001$ \\
\hline
\end{tabular}

CES-D Center for Epidemiological Studies Depression Scale, CI confidence interval, FAMS Functional Assessment of Multiple Sclerosis, MFIS Modified Fatigue Impact Scale, PASAT paced auditory serial addition test

and final examination among those converted because of lack of efficacy rather than AEs.

As our understanding of MS improves, it has become clearer that symptoms beyond disability scores, such as EDSS, are important [23]. For example, fatigue in MS has been correlated not only with neurodegenerative processes that cause functional reorganization resulting in increased metabolic demands [31, 32], but also, recently, with disturbance in central neuronal pathways [33]. Interestingly, in one study, patient-reported fatigue was observed to significantly improve after converting to GA, consistent with previous reports of increased improvement of fatigue symptoms with GA use [26, 34]. Similarly, cognition, correlating with cortical atrophy in MS patients [35], improved significantly from baseline after converting to GA. Cognitive symptoms in MS have been associated with cortical atrophy [35], but it is important to remember that such symptoms in many patients can vary over time and be a result of fatigue. Of course, patients who improve after switching from IFN to GA may do so because they no longer experience the typical flu-like side effects that increase fatigue. Patients also improved significantly on measures of QoL and depression, while mobility scores remained stable. Improvements in QoL were more pronounced in those who converted because of AEs versus lack of efficacy, which is consistent with intolerable AEs, which significantly impact QoL, being eliminated or reduced after conversion to GA.

Depression scores significantly improved during GA treatment in patients who converted due to lack of efficacy, but were unchanged in those who converted because of AEs. Improved scores in patients previously experiencing a lack of efficacy may have been due to a heightened confidence in the ability of their new regimen to slow disease progression.

Taken together, the decrease in ARR and lack of EDSS progression observed in patients who converted to GA therapy represent significant real-world improvements attained by RRMS patients whose disease was not adequately controlled by their previous DMT. This is an important finding, because it points to the ability of GA to modify patient progression on a real-world level, as measured by clinical relapses and other patient-reported outcomes, including fatigue and depression.

Of the 672 patients included in the study, AEs occurred in $15.5 \%$ of patients. These AEs were mainly attributable to injection-site reactions or pain. Because neurodegenerative activity is observed in MS patients even in early stages of the disease [36], it is important to establish rigorous algorithms to optimize treatment in those responding sub-optimally to their original therapy. Should monotherapy not prove optimal, combining a DMT with another treatment could provide an additive effect to control disease progression [37].

This observational study reflects both the limitations and advantages inherent in such a study design. Regression to the mean has been shown to be a common occurrence in longitudinal studies of MS patients with high levels of disease activity and may present a limitation in the present study given that there is no comparison to a matched control cohort [38]. This phenomenon would suggest that patients switching to GA as a consequence of the limited efficacy of prior therapy will tend to return to the average disease state over time, potentially accounting for reductions in the ARR rate. Other limitations include the potential for information or classification bias [39]. However, well-designed observational studies with appropriate statistical techniques provide valuable information, with high generalizability. Further, the overall sample size was relatively small, and sample sizes were not consistent throughout the different assessments (i.e. the same number of patients may not have been examined for fatigue as for cognition, etc.). Thus, it was not possible to pool the patients across all parameters. Further, because of the observational nature of this study, there was a fairly high dropout rate and considerable variability in the availability of patient data for different endpoints. However, the dropout rate included not only patients who left the study but also patients who had to be excluded from the study because of missing data from the participating sites. Nevertheless, the results of observational studies can be used to demonstrate real-world clinical outcomes, including 
Table 5 Most frequently reported adverse events by preferred term and by system organ class $(n=672)$

\begin{tabular}{|c|c|c|}
\hline Adverse events & $\begin{array}{l}\text { Patients, } \\
n(\%)\end{array}$ & $\begin{array}{l}\text { Nun } \\
\text { ever }\end{array}$ \\
\hline Total reported adverse events & $104(15.5)$ & 196 \\
\hline \multicolumn{3}{|c|}{ By system organ class (frequency of cases $\geq 3$ ) } \\
\hline $\begin{array}{l}\text { General disorders and administration } \\
\text { site conditions }\end{array}$ & $50(7.4)$ & 78 \\
\hline Nervous system disorders & $19(2.8)$ & 20 \\
\hline Skin and subcutaneous tissue disorders & $18(2.7)$ & 21 \\
\hline Psychiatric disorders & $11(1.6)$ & 14 \\
\hline $\begin{array}{l}\text { Respiratory, thoracic and mediastinal } \\
\text { disorders }\end{array}$ & $10(1.5)$ & 12 \\
\hline $\begin{array}{l}\text { Musculoskeletal and connective tissue } \\
\text { disorders }\end{array}$ & $8(1.2)$ & 9 \\
\hline Immune system disorders & $7(1.0)$ & 7 \\
\hline Vascular disorders & $7(1.0)$ & 7 \\
\hline Gastrointestinal disorders & $5(0.7)$ & 6 \\
\hline Infections and infestations & $3(0.5)$ & 3 \\
\hline $\begin{array}{l}\text { Neoplasms benign, malignant, and } \\
\text { unspecified }\end{array}$ & $3(0.5)$ & 3 \\
\hline
\end{tabular}

Adverse events by preferred term (frequency of cases $\geq 4$ )

$\begin{array}{lcc}\text { Injection-site pain } & 13(1.9) & 17 \\ \text { Injection-site reaction } & 10(1.5) & 10 \\ \text { Dyspnea } & 8(1.2) & 10 \\ \text { Depression } & 6(0.9) & 6 \\ \text { Hypersensitivity } & 6(0.9) & 6 \\ \text { Headache } & 5(0.7) & 5 \\ \text { Injection site induration } & 5(0.7) & 5 \\ \text { Lipoatrophy } & 5(0.7) & 5 \\ \text { Application site pain } & 4(0.6) & 4 \\ \text { Arthralgia } & 4(0.6) & 4 \\ \text { Fatigue } & 4(0.6) & 4 \\ \text { Flushing } & 4(0.6) & 4 \\ \text { Rash } & 4(0.6) & 4 \\ \text { Syncope } & 4(0.6) & 4\end{array}$

By severity

$\begin{array}{lrr}\text { Serious } & 7(1.0) & 10 \\ \text { Severe } & 18(2.7) & 32 \\ \text { Moderate } & 56(8.3) & 90 \\ \text { Mild } & 41(6.1) & 61 \\ \text { Not reported } & 9(1.3) & 13\end{array}$

Most common severe adverse events

$\begin{array}{lll}\text { Injection-site pain } & 3(0.5) & 4 \\ \text { Dyspnea } & 4(0.6) & 4\end{array}$

Most common moderate adverse events

$\begin{array}{lll}\text { Injection-site pain } & 6(0.9) & 8 \\ \text { Depression } & 6(0.9) & 6\end{array}$

Table 5 continued

\begin{tabular}{|c|c|c|}
\hline Adverse events & $\begin{array}{l}\text { Patients, } \\
n(\%)\end{array}$ & $\begin{array}{l}\text { Number of } \\
\text { events }\end{array}$ \\
\hline Injection-site reaction & $6(0.9)$ & 4 \\
\hline Hypersensitivity & $6(0.9)$ & 4 \\
\hline \multicolumn{3}{|l|}{ Most common mild adverse events } \\
\hline Injection-site pain & $5(0.7)$ & 5 \\
\hline Injection-site reaction & $5(0.7)$ & 5 \\
\hline \multicolumn{3}{|l|}{ Outcome of adverse events } \\
\hline Ongoing at date of report & $49(7.3)$ & 79 \\
\hline Completely resolved & $48(7.1)$ & 84 \\
\hline Resolved with sequelae & $8(1.2)$ & 12 \\
\hline Data missing & $9(1.3)$ & 11 \\
\hline Unknown result & $4(0.6)$ & 10 \\
\hline \multicolumn{3}{|c|}{ Action taken on Copaxone due to adverse events } \\
\hline No action taken & $71(10.6)$ & 128 \\
\hline Treatment permanently discontinued & $31(4.6)$ & 46 \\
\hline Treatment temporarily interrupted & $13(1.9)$ & 19 \\
\hline Data missing & $2(0.4)$ & 2 \\
\hline Dose reduction & $1(0.2)$ & 1 \\
\hline \multicolumn{3}{|l|}{ Patient assessment of adverse events } \\
\hline $\begin{array}{l}\text { Reported improvement after } \\
\text { conversion to GA }\end{array}$ & $430(65.2)$ & N/A \\
\hline $\begin{array}{l}\text { Reported no change after conversion to } \\
\text { GA }\end{array}$ & $192(29.0)$ & N/A \\
\hline $\begin{array}{l}\text { Reported feeling worse after } \\
\text { conversion to GA }\end{array}$ & $38(5.8)$ & N/A \\
\hline
\end{tabular}

improvement to patients' daily lives, and fewer relapses and improved quality of life.

Despite study limitations, our observations corroborate the results of previous studies in which improved treatment response (i.e. reduced ARR, delayed disease progression) was observed in patients who converted from one DMT to another [5, 6, 14, 40-43]. Our findings also emphasize the importance of changing a therapeutic regimen to improve patients' well-being (i.e. QoL, depression, fatigue) and control disease progression while overcoming treatmentrelated barriers (i.e. intolerable AEs) that could compromise compliance among patients responding sub-optimally to their current regimen and result in further disease progression.

Patients whose disease is progressing on their current DMT need to be converted in a timely manner. Future clinical trial designs should include patients converting from one DMT to another as a study arm. These trials could contribute to the development of consensus statements, treatment algorithms, and clinical parameters for 
Table 6 Study termination and most commonly reported reasons for termination $(n=672)$

\begin{tabular}{lc}
\hline Adverse events & Patients, $n(\%)$ \\
\hline Patients discontinuing trial for any reason $^{\mathrm{a}}$ & $174(25.9)$ \\
One reported reason & $156(23.2)$ \\
Two reported reasons & $15(2.2)$ \\
Three reported reasons & $3(0.5)$
\end{tabular}

Most common physician-reported reasons

Lack of efficacy or perceived efficacy $42(6.3)$

Loss to follow-up 40 (6.0)

Adverse events 31 (4.6)

Other 26 (3.9)

Most common patient-reported reasons

Lack of efficacy or perceived efficacy

Consent withdrawn

Fear of adverse events

$8(1.2)$

${ }^{a}$ Patients cited up to three reasons for discontinuing treatment, explaining why the number of total reported reasons for discontinuation (195) exceeds number of discontinuing patients (174)

changing treatment. This is important, as converting treatments is not always necessary and is associated with significant healthcare costs.

Acknowledgments This study was supported by Teva Pharmaceuticals Industries Ltd., Petach Tikva, Israel. The authors would like to thank Ruth Sussman, $\mathrm{PhD}$, who provided editorial support with funding from Teva Pharmaceuticals Industries Ltd., Petach Tikva, Israel. This report is dedicated to the memory of Dr Rafael Lander Delgado.

Conflict of interest Ovidiu A. Bajenaru is a consultant/advisor to, and has received lecture and investigator fees in clinical trials from, Bayer-Schering, Biogen Idec, Merck Serono, Novartis, and Teva. Adriana Carrá has received honoraria from Bago, Bayer-Schering, Biogen Idec, Biosidus, Genzyme, Ivax-Teva, Merck Serono, Novartis, and Teva. Astrid Edland has received honoraria for lectures and conferences from Bayer-Schering, Biogen Idec, Novartis, SanofiAventis, and Teva. She has been a member of advisory boards for Biogen Idec, Genzyme, Novartis, and Teva. Jette L. Frederiksen Battistini has served on scientific advisory boards for and received funding for travel related to these activities, as well as honoraria, from Almirall, Biogen Idec, Merck Serono, Novartis, Sanofi-Aventis, and Teva. She has received speaker honoraria from Biogen Idec, Merck Serono, and Teva, and she has served as an advisor on preclinical development for Takeda. Yossi Gilgun-Sherki is an employee of Teva Pharmaceutical Industries. Olivier Heinzlef, Klimentini E. Karageorgiou, Miguel A. Macías Islas, João C. de Sá, and Nina de Klippel have no conflicts of interest. Anne-Marie Landtblom has received honoraria for lectures and conferences or collaboration in clinical studies from Bayer, Biogen Idec, Sanofi-Aventis, Serono, and Teva. Niall Tubridy has received unrestricted research support from BayerSchering, Biogen Idec, and Sanofi-Aventis. Tjalf Ziemssen has received speaker honoraria from Almirall, Bayer-Schering, Biogen Idec, Genzyme, GSK, Sanofi-Aventis, Merck Serono, MSD, Novartis, and Teva. He serves as a consultant for Bayer-Schering, Biogen Idec, Novartis, and Teva, and he receives research support from the
Deutsche Diabetes Stiftung, Hertie Foundation, the Robert Pfleger Foundation, and the Roland Ernst Foundation.

Open Access This article is distributed under the terms of the Creative Commons Attribution License which permits any use, distribution, and reproduction in any medium, provided the original author(s) and the source are credited.

\section{References}

1. Loma I, Heyman R (2011) Multiple sclerosis: pathogenesis and treatment. Curr Neuropharmacol 9:409-416

2. Comi G, Filippi M, Wolinsky JS (2001) European/Canadian multicenter, double-blind, randomized, placebo-controlled study of the effects of glatiramer acetate on magnetic resonance imaging-measured disease activity and burden in patients with relapsing multiple sclerosis. European/Canadian Glatiramer Acetate Study Group. Ann Neurol 49:290-297

3. The IFNB Multiple Sclerosis Study Group (1993) Interferon beta$1 \mathrm{~b}$ is effective in relapsing-remitting multiple sclerosis I: clinical results of a multicenter, randomized, double-blind, placebo-controlled trial. Neurology 43:655-661

4. Ziemssen T (2009) Multiple sclerosis beyond EDSS: depression and fatigue. J Neurol Sci 277(Suppl 1):S37-S41

5. Coyle PK (2008) Switching algorithms: from one immunomodulatory agent to another. J Neurol 255(Suppl 1):44-50. doi:10. 1007/s00415-008-1007-3.:44-50

6. Rio J, Tintore M, Sastre-Garriga J, Nos C, Castillo J, Tur C et al (2012) Change in the clinical activity of multiple sclerosis after treatment switch for suboptimal response. Eur J Neurol 19:899-904

7. Balak DM, Hengstman GJ, Cakmak A, Thio HB (2012) Cutaneous adverse events associated with disease-modifying treatment in multiple sclerosis: a systematic review. Mult Scler 18:1705-1717

8. Costello K, Kennedy P, Scanzillo J (2008) Recognizing nonadherence in patients with multiple sclerosis and maintaining treatment adherence in the long term. Medscape J Med 10:225

9. Krumbholz M, Pellkofer H, Gold R, Hoffmann LA, Hohlfeld R, Kumpfel $T$ (2007) Delayed allergic reaction to natalizumab associated with early formation of neutralizing antibodies. Arch Neurol 64:1331-1333

10. Sorensen PS, Jensen PE, Haghikia A, Lundkvist M, Vedeler C, Sellebjerg F et al (2011) Occurrence of antibodies against natalizumab in relapsing multiple sclerosis patients treated with natalizumab. Mult Scler 17:1074-1078

11. Goodin DS, Frohman EM, Hurwitz B, O'Connor PW, Oger JJ, Reder AT et al (2007) Neutralizing antibodies to interferon beta: assessment of their clinical and radiographic impact: an evidence report: report of the Therapeutics and Technology Assessment Subcommittee of the American Academy of Neurology. Neurology 68:977-984

12. Coyle PK (2013) Switching therapies in multiple sclerosis. CNS Drugs 27:239-247

13. Caon C, Din M, Ching W, Tselis A, Lisak R, Khan O (2006) Clinical course after change of immunomodulating therapy in relapsing-remitting multiple sclerosis. Eur J Neurol 13:471-474

14. Healy BC, Glanz BI, Stankiewicz J, Buckle G, Weiner H, Chitnis $\mathrm{T}$ (2010) A method for evaluating treatment switching criteria in multiple sclerosis. Mult Scler 16:1483-1489

15. Gneiss C, Koudouovoh-Tripp PM, Ropele S, Gotwald T, Ehling $\mathrm{R}$, Lutterotti A et al (2009) Influence of interferon-beta therapy switching on neutralizing antibody titres: results from the Austrian Switch Study. Mult Scler 15:1481-1488 
16. Carra A, Onaha P, Luetic G, Burgos M, Crespo E, Deri N et al (2008) Therapeutic outcome 3 years after switching of immunomodulatory therapies in patients with relapsing-remitting multiple sclerosis in Argentina. Eur J Neurol 15:386-393

17. Zwibel HL (2006) Glatiramer acetate in treatment-naive and prior interferon-beta-1b-treated multiple sclerosis patients. Acta Neurol Scand 113:378-386

18. Caon C (2009) Maximising therapeutic outcomes in patients failing on current therapy. J Neurol Sci 277(Suppl 1):S33-S36. doi:10.1016/S0022-510X-3

19. Prosperini L, Gianni C, Leonardi L, De Giglio L, Borriello G, Galgani S et al (2012) Escalation to natalizumab or switching among immunomodulators in relapsing multiple sclerosis. Mult Scler 18:64-71

20. Bezabeh S, Flowers CM, Kortepeter C, Avigan M (2010) Clinically significant liver injury in patients treated with natalizumab. Aliment Pharmacol Ther 31:1028-1035

21. Teva Neuroscience Inc. (2012) Copaxone ${ }^{\circledR}$ (glatiramer acetate) solution for subcutaneous injection: full prescribing information, FDA-approved labeling

22. TEVA Pharmaceutical Industries Ltd. (2013) Data on file

23. Ziemssen T, Neuhaus O, Hohlfeld R (2001) Risk-benefit assessment of glatiramer acetate in multiple sclerosis. Drug Saf 24:979-990

24. Schrempf W, Ziemssen T (2007) Glatiramer acetate: mechanisms of action in multiple sclerosis. Autoimmun Rev 6:469-475

25. Ziemssen T, Hoffman J, Apfel R, Kern S (2008) Effects of glatiramer acetate on fatigue and days of absence from work in firsttime treated relapsing-remitting multiple sclerosis. Health Qual Life Outcomes 6:67

26. Gronwall DM (1977) Paced auditory serial-addition task: a measure of recovery from concussion. Percept Mot Skills 44:367-373

27. Fisk JD, Ritvo PG, Ross L, Haase DA, Marrie TJ, Schlech WF (1994) Measuring the functional impact of fatigue: initial validation of the fatigue impact scale. Clin Infect Dis 18(Suppl 1):S79-S83

28. Neurostatus $e$ test. Murbacherstrasse 34, 4056 Basel, Switzerland: Neurostatus Systems GmbH, 13 AD

29. Cella DF, Dineen K, Arnason B, Reder A, Webster KA, Karabatsos $G$ et al (1996) Validation of the functional assessment of multiple sclerosis quality of life instrument. Neurology 47:129-139

30. Weissman MM, Sholomskas D, Pottenger M, Prusoff BA, Locke BZ (1977) Assessing depressive symptoms in five psychiatric populations: a validation study. Am J Epidemiol 106:203-214

31. Kos D, Kerckhofs E, Nagels G, D' hooghe MB, Ilsbrouckx S (2008) Origin of fatigue in MS: review of the literature. Neuro Rehabil Neuro Repair 22:91-100
32. Riccitelli G, Rocca MA, Forn C, Colombo B, Comi G, Filippi M (2011) Voxelwise assessment of the regional distribution of damage in the brains of patients with multiple sclerosis and fatigue. AJNR Am J Neuroradiol 32:874-879

33. Engström M, Flensner G, Landtblom A-M, Ek A-C, Karlsson T (2013) Thalamo-striato-cortical determinants of fatigue in multiple sclerosis. Brain Behav 3:715-728

34. Metz LM, Patten SB, Archibald CJ, Bakker JI, Harris CJ, Patry DG et al (2004) The effect of immunomodulatory treatment on multiple sclerosis fatigue. J Neurol Neurosurg Psychiatry 75:1045-1047

35. Benedict RH, Hulst HE, Bergsland N, Schoonheim MM, Dwyer MG, Weinstock-Guttman B et al (2013) Clinical significance of atrophy and white matter mean diffusivity within the thalamus of multiple sclerosis patients. Mult Scler 19:1478-1484

36. Filippi M, Bozzali M, Rovaris M, Gonen O, Kesavadas C, Ghezzi A et al (2003) Evidence for widespread axonal damage at the earliest clinical stage of multiple sclerosis. Brain 126:433-437

37. De Stefano N, Filippi M, Hawkins C (2008) Short-term combination of glatiramer acetate with i.v. steroid treatment preceding treatment with GA alone assessed by MRI-disease activity in patients with relapsing-remitting multiple sclerosis. J Neurol Sci 266:44-50

38. Martinez-Yelamos S, Martinez-Yelamos A, Martin Ozaeta G, Casado V, Carmona O, Arbizu T (2006) Regression to the mean in multiple sclerosis. Mult Scler 12:826-829

39. Hazel CA, Petre KL, Armstrong RA, Benson MT, Frost NA (2000) Visual function and subjective quality of life compared in subjects with acquired macular disease. Invest Ophthalmol Vis Sci 41:1309-1315

40. Portaccio E, Zipoli V, Siracusa G, Sorbi S, Amato MP (2009) Switching to second-line therapies in interferon-beta-treated relapsing-remitting multiple sclerosis patients. Eur Neurol 61:177-182

41. Gajofatto A, Bacchetti P, Grimes B, High A, Waubant E (2009) Switching first-line disease-modifying therapy after failure: impact on the course of relapsing-remitting multiple sclerosis. Mult Scler 15:50-58

42. Capobianco M, Rizzo A, Malucchi S, Sperli F, Di Sapio A, Oggero A et al (2008) Glatiramer acetate is a treatment option in neutralising antibodies to interferon-beta-positive patients. Neurol Sci 29(Suppl 2):S227-S229

43. Fernandez O (2012) Clinical utility of glatiramer acetate in the management of relapse frequency in multiple sclerosis. J Cent Nerv Syst Dis 4:117-133 